Scientific Paper

Doi: http://dx.doi.org/10.1590/1809-4430-Eng.Agric.v42n1e20200149/2022

\title{
FUZZY MODELING FOR RAPID COOLING OF TABLE GRAPES IN DIFFERENT PLASTIC FILM BAGS
}

\author{
Magno do N. Amorim ${ }^{1 *}$, Isadora B. Miranda ${ }^{2}$, Ítalo E. dos A. Santos ${ }^{1}$, \\ Dian Lourençoni ${ }^{1}$, Silvia H. N. Turco ${ }^{1}$
}

${ }^{1 *}$ Corresponding author. Universidade Federal do Vale do São Francisco - UNIVASF/ Juazeiro - BA, Brasil. E-mail: magno_amorim27@hotmail.com | ORCID ID: https://orcid.org/0000-0003-0332-2905

\section{KEYWORDS}

Vitis vinifera L., artificial intelligence, palletization level, relative humidity, weight loss.

\begin{abstract}
Rapid cooling is necessary to remove heat from fruit; however, it directly affects the water loss of grapes under certain conditions. Fuzzy logic is an important theory for analyzing results as it simplifies the assimilation of the phenomena through refined adjustments, allowing the prediction of the weight loss of fruits in relation to rapid cooling conditions. The objective of this study was to develop a fuzzy model that could predict weight loss as a function of the rapid cooling of table grapes in different plastic film bags. Modeling was performed using three types of plastic film bags (micro-perforated, macro-perforated, and non-perforated) at three levels of palletization (lower, intermediate, and upper), arranged in an experimental design in randomized blocks, in a $3 \times 3$ factorial scheme, with three blocks. The influence of the relative humidity and amplitude of humidity on the variable weight loss percentage of the Arra 15 grape variety was measured. The average percentage error of the fuzzy model was $9.78 \%$. The intermediate level alone showed an error of $4.02 \%$. Thus, the developed fuzzy model provided a good prediction of the weight loss of table grapes.
\end{abstract}

\section{INTRODUCTION}

Depending on the region and time of year, after harvesting, table grapes arrive at the packing houses with at high temperatures and require rapid cooling to remove heat so that they can be stored under proper conditions, thus reducing physiological processes, metabolic activity, and enzymatic and chemical reactions (Franco et al., 2017).

The relative humidity $(\mathrm{RH})$ in the rapid cooling chamber should be considered because exposure of the product to a $\mathrm{RH}$ outside its ideal range leads to a noticeable drop in product quality, which is sufficient to prevent its commercialization (Franco et al., 2017; Spagnol et al., 2018). During rapid cooling under inadequate $\mathrm{RH}$ conditions, fruit weight loss is caused by the high flow of dry air from the environment, which removes water from the fruit owing to the pressure differential (Amorim et al., 2020).

Another factor contributing to the reduction of weight loss in grapes is the use of packaging that promotes a modified atmosphere and limited gas exchange because of the polymer properties acting as a barrier that are essential for preserving fruit metabolism (Siqueira et al., 2017). These packages are known as plastic film bags and primarily prevent $\mathrm{CO}_{2}$ from leaving and $\mathrm{O}_{2}$ from entering. According to Admane et al. (2018), such packaging favors lower water loss and maintains the mechanical and chemical characteristics of the grapes.

Therefore, a mathematical model that predicts the amount of weight lost by table grapes when subjected to various plastic film bags and $\mathrm{RH}$ ranges during rapid cooling is of great relevance for decision making and facilitating the perception of how long fruits can be left in storage without major financial losses.

Among the possible developed models, those based on the theory of fuzzy sets have proven suitable (Lourençoni et al., 2019b). This theory states that variables do not accept precise values, providing degrees of pertinence between the

\footnotetext{
${ }^{1}$ Universidade Federal do Vale do São Francisco - UNIVASF/ Juazeiro - BA, Brasil.

${ }^{2}$ Universidade Federal de Campina Grande - UFCG/ Campina Grande - PB, Brasil.

Area Editor: Jefferson Vieira José

Received in: 9-12-2020

Accepted in: 11-30-2021
} 
elements, and elaborating numerous rules to facilitate the modeling of more complex problems, making it more straightforward (Rignel et al., 2011).

Fuzzy logic has been gaining prominence using mathematics and computational theories with more refined adjustments than the regression method, making it simpler to assimilate phenomena from many areas and essential for analyzing results (Viais Neto et al., 2019).

Thus, the objective of the present study was to develop a fuzzy model that could predict weight loss as a function of the cooling speed of table grapes in different plastic film bags.

\section{MATERIAL AND METHODS}

The experiment was conducted from June to August 2018 in the packing house of a commercial agricultural farm located in the Submédio do São Francisco region. The table grape variety Arra 15 was used, which is a seedless fruit with cylindrically shaped long berries, a light creamy green color, and bright and waxy skin.

The culture system was trellised, with the rootstock IAC 313 that is very strong and vigorous. The spacing of the vines was $3.5 \mathrm{~m}$ between rows (streets) and $3.0 \mathrm{~m}$ between plants, with cultural and phytosanitary treatments undertaken according to the technical recommendations for the region.

The experimental design used was a randomized block design, arranged in a $3 \times 3$ factorial scheme, with three blocks and each block was represented by different days of palletization. The first factor corresponded to the type of plastic film bag used in the palletization (traditional micro-perforated plastic film bag used by the market
[BMT], non-perforated plastic film bag [BSP], and macroperforated plastic film bag [BMG]) and the second factor was the pallet height levels in relation to the floor level (lower $=0.20 \mathrm{~m}$, intermediate $=1.16 \mathrm{~m}$, and upper $=2.04 \mathrm{~m}$ ).

For the fuzzy modeling, the RH data of the table grapes were obtained using Hobo ${ }^{\circledR}$ U12-013 dataloggers (accuracy of $\pm 2.5 \%$ ). The equipment was placed in plastic bowls, in a central position in the boxes, together with the grapes, and data were collected every 5 min. Data were collected when the pallets were in the rapid cooling chamber (14 $\mathrm{h}$ and $30 \mathrm{~min}$ ) and then the pallets were transferred to the storage chamber. The temperature was $0.0 \pm 0.5^{\circ} \mathrm{C}$ and $2.5 \pm 0.5{ }^{\circ} \mathrm{C}$ in the rapid cooling chamber and storage chamber, respectively. The RH during storage was $80 \pm 3 \%$.

The RH data were calculated by averaging the values recorded during the rapid cooling chamber operation time and the RH amplitude was determined by subtracting the highest value recorded from the lowest. The weight values of the grapes were measured before the fruit entered the rapid cooling chamber and after 60 days of storage in the cold chamber, making it possible to calculate the loss of mass during this interval. A total of 10 plastic bowls containing grapes were measured during each treatment and block.

The development and validation of the fuzzy model were performed using the MATLAB ${ }^{\circledR}$ Fuzzy Toolbox ${ }^{\circledR}$ platform and the Mandani inference method (Mandani, 1976), which defines logical connectives to establish the rule base. The input variables used for the development of the system were the mean RH (RHm), RH amplitude ( $\lambda \mathrm{RH})$, and plastic film bags, represented by trapezoidal pertinence curves (Figure 1). In a study by Lourençoni et al. (2019a), when evaluating different combinations of pertinence curves, all combinations provided adequate prediction responses. 

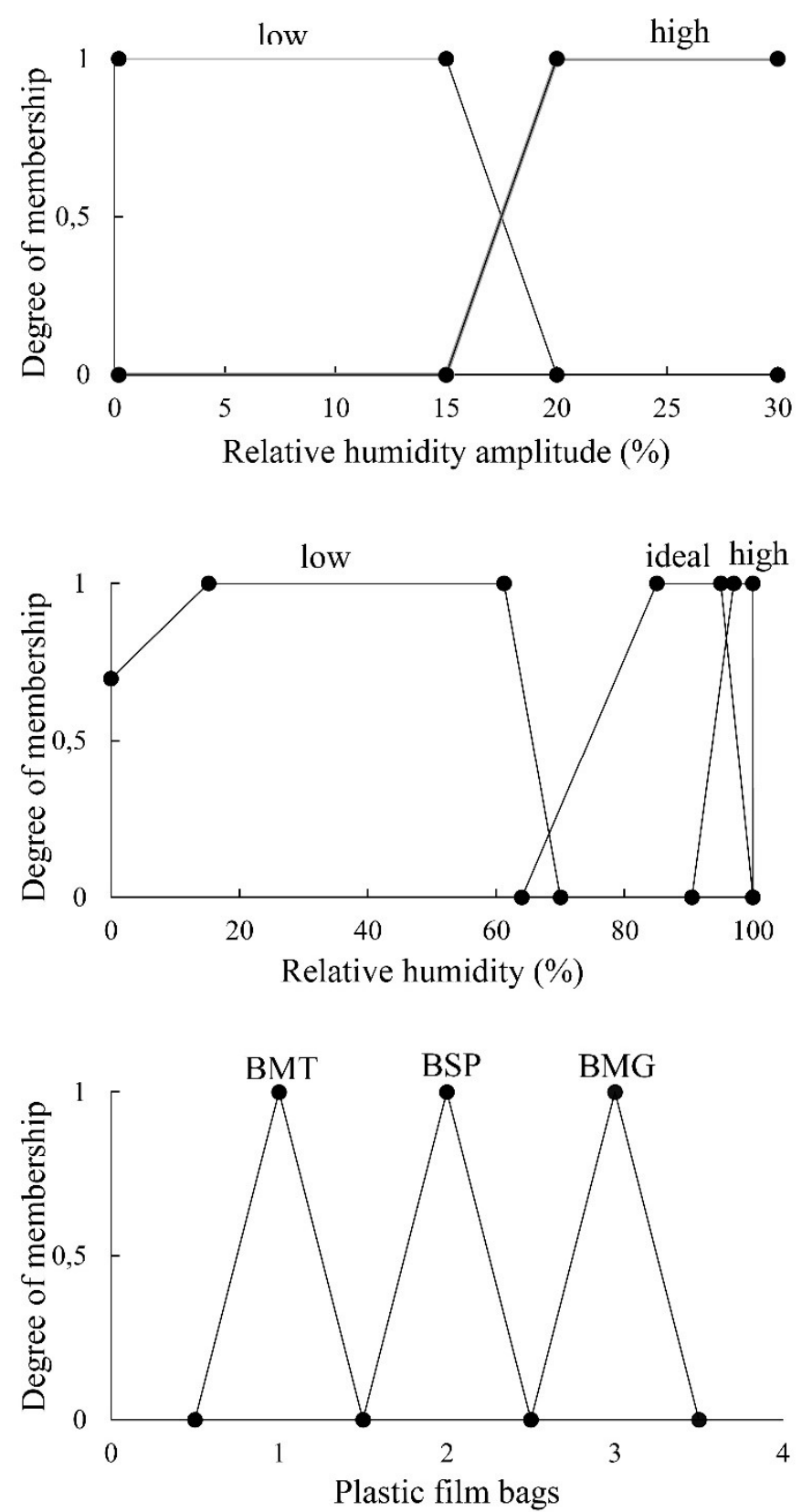

FIGURE 1. Membership functions for the input variables: (a) relative humidity amplitude - $\lambda$ RH, (b) average relative humidity, and (c) plastic films bags.

Based on the input variables and using the experimental data as a reference, the fuzzy model predicted weight loss (WL) as the output variable, which was characterized by a trapezoidal pertinence curve (Figure 2). The defuzzification was performed using the center of gravity method, which converts the fuzzy set from inference into numerical values (Leite et al., 2010).

The developed model characterized the loss of mass as optimal, adequate, and bad, regarding the average moisture, moisture amplitude, and plastic film bags during the rapid cooling of the table grapes. Parameter classification was performed using bibliographical surveys of studies that had undertaken similar processes to the present experiment, such as those by Amorim et al. (2020) and Santos et al. (2019), and included the pertinence functions and rule base. 


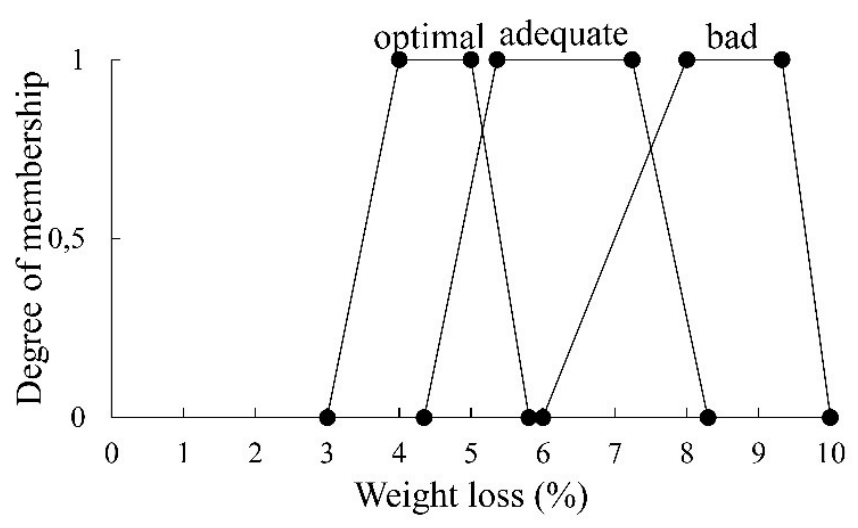

FIGURE 2. Membership functions for the output variable weight loss (WL).

According to the combinations of variables, RHm, $\lambda \mathrm{RH}$, and plastic film bags, 18 rules were defined (Table 1) using four experts with experience in fuzzy modeling
(Cornelissen et al., 2002). Because all rules have the same importance for determining the system responses, a weighting factor of 1 was adopted.

TABLE 1. Set of fuzzy inference rules for weight loss of table grapes.

\begin{tabular}{cc}
\hline & Rules \\
\hline 1 & If ( $\lambda R H$ is low) and (RHm is low) and (Plastic film bag is BMT), then (WL is bad) \\
3 & If ( $\lambda R H$ is low) and (RHm is low) and (Plastic film bag is BSP), then (WL is adequate) \\
4 & If ( $\lambda R H$ is low) and (RHm is low) and (Plastic film bag is BMG), then (WL is bad) \\
5 & If ( $\lambda R H$ is low) and (RHm is optimal) and (Plastic film bag is BMT), then (WL is adequate) \\
6 & If ( $\lambda R H$ is low) and (RHm is optimal) and (Plastic film bag is BSP), then (WL is optimal) \\
7 & If ( $\lambda R H$ is low) and (RHm is optimal) and (Plastic film bag is BMG), then (WL is adequate) \\
8 & If ( $\lambda R H$ is low) and (RHm is high) and (Plastic film bag is BMT), then (WL is optimal) \\
9 & If ( $\lambda R H$ is low) and (RHm is high) and (Plastic film bag is BSP), then (WL is optimal) \\
10 & If ( $\lambda R H$ is low) and (RHm is high) and (Plastic film bag is BMG), then (WL is optimal) \\
11 & If ( $\lambda R H$ is high) and (RHm is low) and (Plastic film bag is BMT), then (WL is bad) \\
12 & If ( $\lambda R H$ is high) and (RHm is low) and (Plastic film bag is BSP), then (WL is bad) \\
13 & If ( $\lambda R H$ is high) and (RHm is low) and (Plastic film bag is BMG), then (WL is bad) \\
14 & If ( $\lambda R H$ is high) and (RHm is optimal) and (Plastic film bag is BMT), then (WL is adequate) \\
15 & If ( $\lambda R H$ is high) and (RHm is optimal) and (Plastic film bag is BSP), then (WL is optimal) \\
16 & If ( $\lambda R H$ is high) and (RHm is high) and (Plastic film bag is BMT), then (WL is adequate) \\
17 & If ( $\lambda R H$ is high) and (RHm is high) and (Plastic film bag is BSP), then (WL is optimal) \\
18 & If ( $\lambda R H$ is high) and (RHm is high) and (Plastic film bag is BMG), then (WL is adequate)
\end{tabular}

Legend: RHm, average relative humidity; $\lambda$ RH, relative humidity range; WL, weight loss; BMT, micro-perforated plastic film bag; BSP, nonperforated plastic film bag; BMG, macro-perforated plastic film bag.

\section{RESULTS AND DISCUSSION}

Fuzzy model fitting was performed based on the data collected in the experiment during rapid cooling and storage for 60 days (Table 2). The average model error for predicting WL was $9.78 \%$. 
TABLE 2. Fuzzy model during rapid cooling after 60 days of storage of table grapes.

\begin{tabular}{ccccccc}
\hline \multirow{2}{*}{ Plastic film bags } & Level & $\begin{array}{c}\text { RHm } \\
(\%)\end{array}$ & $\begin{array}{c}\lambda \text { RH } \\
(\%)\end{array}$ & $\begin{array}{c}\text { WL } \\
(\%)\end{array}$ & $\begin{array}{c}\text { WLs } \\
(\%)\end{array}$ & $\begin{array}{c}\text { Error } \\
(\%)\end{array}$ \\
\hline \multirow{3}{*}{ BMT } & lower & 62.50 & 29.63 & 6.85 & 8.25 & 20.37 \\
& intermediate & 65.01 & 24.03 & 8.30 & 8.05 & 3.03 \\
& upper & 68.30 & 21,27 & 9.75 & 7.16 & 26.58 \\
\hline \multirow{2}{*}{ BSP } & lower & 81.86 & 8.97 & 4.80 & 4.44 & 7.55 \\
& intermediate & 86.96 & 3.87 & 4.66 & 4.44 & 4.69 \\
& upper & 87.29 & 10.51 & 5.06 & 4.44 & 12.16 \\
\hline \multirow{2}{*}{ BMG } & lower & 67.46 & 22.70 & 7.20 & 7.49 & 4.02 \\
& intermediate & 59.68 & 29.28 & 7.93 & 8.28 & 4.35 \\
& upper & 68.13 & 20.90 & 7.64 & 7.24 & 5.23 \\
\hline Mean & & & & & & 9.78 \\
\hline
\end{tabular}

Legend: RHm, average relative humidity; $\lambda$ RH, relative humidity amplitude; WL, weight loss; WLs, weight loss simulated by the model.

Table 2 shows that at the upper level, the model error was higher than that of the other levels. According to Hoang et al. (2015), in a pallet, it is difficult to obtain uniform storage conditions owing to the heterogeneous flow and the variation of the heat transfer coefficient in different positions of the pallet, whereas Getahun et al. (2017) stated that in the lower level, heat transfer was higher than in the intermediate and upper levels.

The largest percentage errors occurred at the top levels in all plastic film bags, indicating that the environment had a strong influence on the top pallet position. According to Pham et al. (2019), products located in the upper layers of the pallet have more contact with the ambient chamber air, where the opening for people to enter and the insertion of new pallets contribute to a loss of mass and consequently increases the modeling error of this palletization level.

The intermediate position represents the most critical position of the pallet; in a test performed by Barbin et al. (2010), the central layer of the pallet had difficulties in exchanging heat compared to the lower and upper layers. According to Hoang et al. (2015), this central region is the slow cooling zone, indicating that it is the closest to the actual conditions in the refrigerated storage of table grapes. When analyzing the intermediate level alone in the present study, a mean percentage error of $4.02 \%$ was obtained, indicating that the model had an accuracy of $95.98 \%$ for pallet conditions.

Associated with heat transfer is the difference in $\mathrm{RH}$ between each level, where high values prevent high water transfer from the fruit to the environment due to the pressure differential. Liquid water moves through the membranes of plant tissues and escapes into the air present in the intercellular spaces as water in vapor form, which is subsequently transferred to the environment (Pereira et al., 2018).

Furthermore, the low humidity amplitude associated with high RH showed that the environment was maintained at adequate levels during the quick cooling process, leading to lower WL. Low RH associated with high humidity amplitude indicates that the fruit had fast cooling under critical conditions, directly affecting the WL increase. High amplitude and RH indicate that the grapes were outside the ideal range at certain times, leading to intermediate losses.

According to Pereira et al. (2018), the weight of grapes constantly decreases over time; however, this loss occurs more slowly depending on the RH conditions. Pinto et al. (2015) stated that the ideal humidity range for table grapes was between $90 \%$ and $95 \%$ for greater maintenance of product quality.

Another factor contributing to maintaining the quality of table grapes is using plastic film bags. Santos et al. (2019) showed that they created an environment with a modified atmosphere inside the packages. The BSP showed lower WLs due to less influence of the ambient air inside the packages, which prevents water loss, corroborating the findings of Amorim et al. (2020).

In a study conducted with non-perforated plastic film bags, Santos et al. (2019) found that the WL due to dehydration was up to five times lower than that of the microand macro-perforated plastic film bags sold in the market.

Cia et al. (2010) conducted a study with a modified atmosphere and refrigeration for the postharvest preservation of table grapes and found that the WL reduction was directly related to the water vapor transmission rate of the package; the lower the transmission rate, the lower the water vapor pressure deficit and the higher the RH inside the package, reducing the transpiration of the grapes, which occurs in the non-perforated plastic film bag, resulting in low mass loss.

To validate the fuzzy model, a simple linear regression was performed, and with the adjustment of the line passing through the origin, the results showed a coefficient of determination of $\mathrm{R}^{2}=0.6585$ (Figure 3), indicating an adequate model accuracy for predicting the WL of table grapes. 


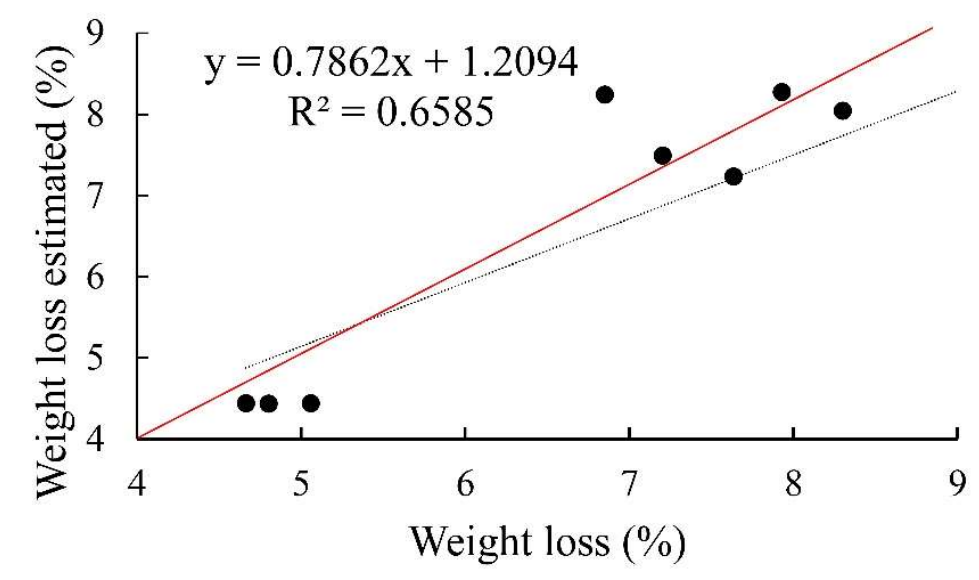

FIGURE 3. Linear regression for the output variable of weight loss of table grapes as a function of the values estimated by the fuzzy model and experimentally measured values.

The fuzzy model obtained a lower error than the simple linear regression because the model makes use of mathematics and computational theories with more refined adjustments than the regression (Viais Neto et al., 2019).

\section{CONCLUSIONS}

The developed fuzzy model provided satisfactory predictions for the WL of table grapes and adequately described the behavior of the fruit regarding amplitude and $\mathrm{RH}$ in which they were subjected during rapid cooling and the type of plastic bag. An average accuracy of $90.22 \%$ for all pallet levels was found and an average accuracy of 95.98\% when considering only the intermediate level, representing the actual pallet conditions.

\section{REFERENCES}

Admane N, Genovese F, Altieri G, Tauriello A, Trani A, Gambacorta G, Verrastro V, Renzo GCD (2018) Effect of ozone or carbon dioxide pre-treatment during long-term storage of organic table grapes with modified atmosphere packaging. Food Science and Technology 98:170-178. DOI: https://doi.org/10.1016/j.lwt.2018.08.041

Amorim MN, Miranda IS, Santos IEA, Turco SH, Caçula BTS, Lourençoni D, Guimarães MJM (2020) Plastic film bags on the refrigeration of table grapes. Revista Brasileira de Ciências Agrárias 15(4):e8415. DOI:

https://doi.org/10.5039/agraria.v15i4a8415

Barbin DF, Neves Filho LC, Silveira Junior V (2009) Processo de congelamento em túnel portátil com convercção forçada por exaustão e insuflação para paletes. Ciência e Tecnologia de Alimentos 29(3):667-675.

Cia P, Benato EA, Valentini SRT, Sanches J, Ponzo FS, Flôres D, Terra MM (2010) Atmosfera modificada e refrigeração para conservação pós-colheita de uva 'Niagara Rosada'. Pesquisa Agropecuária Brasileira 45(10):10581065. DOI: https://doi.org/10.1590/S0100204X2010001000002

Cornelissen AMG, Van Den Berg J, Koops WJ, Kaymak U (2002). Elicitation of expert knowledge for fuzzy evaluation of agricultural production systems. Agriculture, ecosystems \& environment 95(1):1-18. DOI:

https://doi.org/10.1016/S0167-8809(02)00174-3
Franco SS, Villa AAO, Costa JAP (2017)

Condicionamento de alimentos em câmaras frigorígenas: uma visão técnica. Revista Cientec 9(3):121-138.

Getahun S, Ambaw A, Delele M, Meyer CJ, Opara UL (2017) Analysis of airflow and heat transfer inside fruit packed refrigerated shipping container: Part I e Model development and validation. Journal of Food Engineering 203:58-68. DOI:

http://dx.doi.org/10.1016/j.jfoodeng.2017.02.010

Hoang HM, Duret S, Flick D, Laguerre O (2015)

Preliminary study of airflow and heat transfer in a cold room filled with apple pallets: Comparison between two modelling approaches and experimental results. Applied Thermal Engineering 76:367-381. DOI:

https://doi.org/10.1016/j.applthermaleng.2014.11.012

Leite MS, Fileti AMF, Silva FV (2010) Desenvolvimento e aplicação experimental de controladores fuzzy e convencional em um bioprocesso. Revista Controle e Automação 21(2):147-158

Lourençoni D, Abreu PGD, Yanagi Junior T, Campos AT, Yanagi SDN (2019a) Pertinence curves in fuzzy modeling of the productive responses of broilers. Engenharia Agrícola 39(3):265-271. DOI: https://doi.org/10.1590/1809-4430-eng.agric.v39n3p265$271 / 2019$

Lourençoni D, Yanagi Junior T, Abreu PG, Campos AT, Yanagi SNM (2019b) Productive responses from broiler chickens raised in different commercial production systems - part i: fuzzy modeling. Engenharia Agrícola 39(1):1-10. DOI: http://dx.doi.org/10.1590/1809-4430eng.agric.v39n1p1-10/2019

Mandani EH (1976) Advances in the linguistic syntesis of fuzzy controllers. International Journal of Man-Machine Studies 8(6):669-678.

Pereira R, Silva RGB, Spagnol WA, Silveira Junior V (2018) Water loss in table grapes: model development and validation under dynamic storage conditions. Food Science and Technology 38(3):473-479. DOI: https://doi.org/10.1590/1678-457X.08817 
Pham AT, Moureh J, Flick D (2019) Experimental characterization of heat transfer within a pallet of product generating heat. Journal of Food Engineering 247:115-125. DOI: https://doi.org/10.1016/j.jfoodeng.2018.12.003

Pinto JAV, Schorr MRW, Thewes DLC, Both V, Brackmann A, Fronza D (2015) Relative humidity during cold storage on Postharvest quality of 'Niagara Rosada' table grapes. Ciência Rural 45(3):386-391. DOI: http://dx.doi.org/10.1590/0103-8478cr20130307

Rignel DGS, Chenci GP, Lucas CA (2011) Uma introdução a lógica fuzzy. Revista Eletrônica de Sistemas de Informação e Gestão Tecnológica 1(1):17-28.

Santos LHR, Silva JC, Figueiredo Neto A, Silva EP, Azevedo TP, Costa JDS (2019) Qualidade de uva 'arra 15' armazenada em atmosfera modificada em bolsões de filme plástico. Revista Iberoamericana de Tecnología Postcosecha 20(2):164-176.
Siqueira CL, Almeida HJ, Serpa MFP, Batista PSC, Mizobutsi GP (2017) Modified atmosphere together with refrigeration in the conservation of bananas resistant to black Sigatoka. Revista Ciência Agronômica 48(4):614624. DOI: http://dx.doi.org/10.5935/1806-6690.20170071

Spagnol WA, Silveira Junior V, Pereira E, Guimarães Filho N (2018) Redução de perdas nas cadeias de frutas e hortaliças pela análise da vida útil dinâmica. Brazilian Journal of Food Technology 21:1-10. DOI: http://dx.doi.org/10.1590/1981-6723.07016

Viais Neto DS, Cremasco CP, Bordin D, Putti FF, Silva Junior JF, Gabriel Filho LRA (2019) Fuzzy modeling of the effects of irrigation and water salinity in harvest point of tomato crop. Part i: description of the method. Engenharia Agrícola 39(3):294-304. DOI: http://dx.doi.org/10.1590/1809-4430Eng.Agric.v39n3p294-304/2019 